\title{
Sex Linked
}

National Human Genome Research Institute (NHGRI)

\section{Source}

National Human Genome Research Institute (NHGRI). Sex Linked.
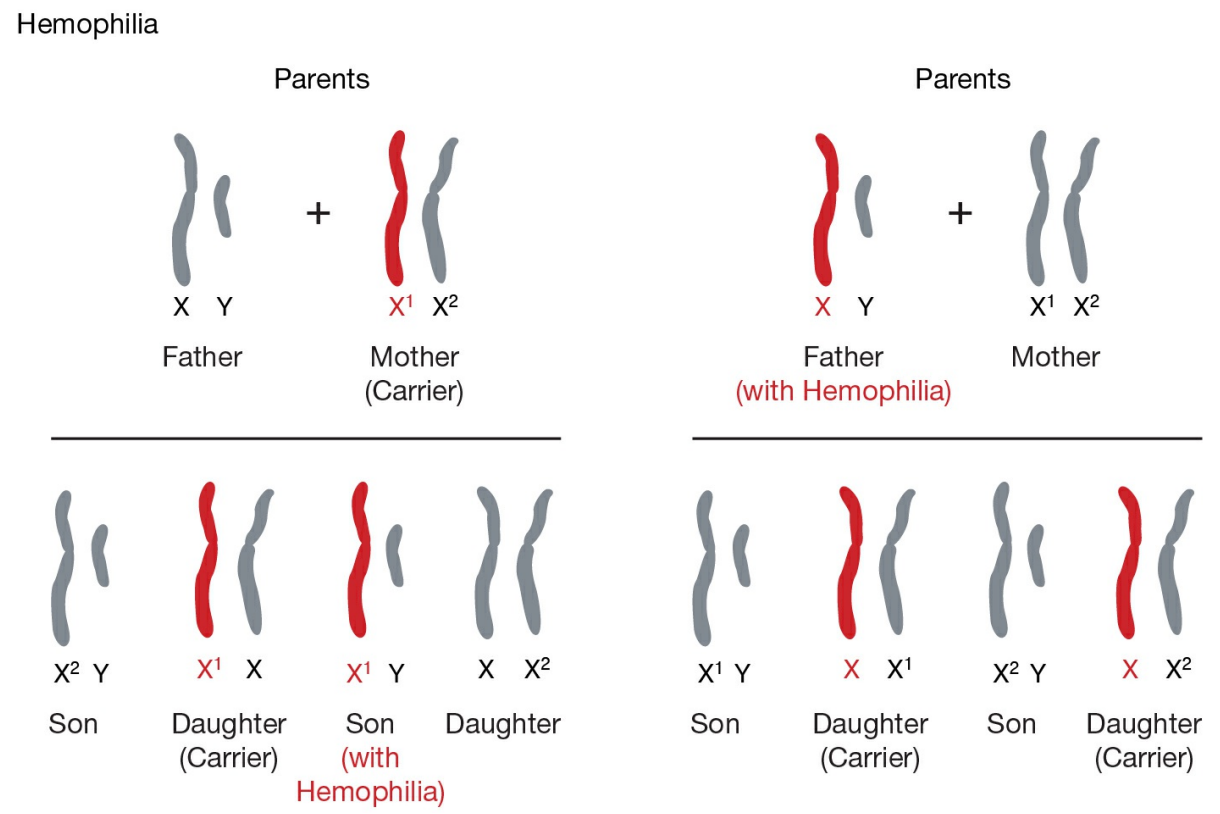

Sex linked is a trait in which a gene is located on a sex chromosome. In humans, the term generally refers to traits that are influenced by genes on the $\mathrm{X}$ chromosome. This is because the $\mathrm{X}$ chromosome is large and contains many more genes than the smaller $\mathrm{Y}$ chromosome. In a sex-linked disease, it is usually males who are affected because they have a single copy of X chromosome that carries the mutation. In females, the effect of the mutation may be masked by the second healthy copy of the X chromosome. 